\title{
Does Seasonality and Stochastic Cycles Affect Output Growth in Nigeria? Lessons for Development Planning
}

\author{
*Kanayo Ogujiuba ${ }^{1,2}$, Terfa W. Abraham², Nancy Stiegler ${ }^{1}$ \\ ${ }^{1}$ Department of Statistics and Population Studies, University of Western Cape, South Africa \\ ${ }^{2}$ Research Division, National Institute for Legislative Studies (NILS), Abuja - Nigeria \\ *kannyog@gmail.com
}

\begin{abstract}
This paper examines the seasonality and stochastic cycle associated with GDP growth in Nigeria using two measures of filter. Our findings include, that the Christiano \& Fitzgerald (2003) filter removed lowperiodicity stochastic cycles associated with output growth in Nigeria compared to the Hodrick Prescott filter. The smoothed GDP trend further revealed that growth in Nigeria was higher but unstable in periods of development planning than in periods without development plans. This suggests that development planning in Nigeria was not accompanied by judicious mix of fiscal and monetary policy in the 1980s/1990s. Likewise, effort to achieve sustainable growth and development, since the return to democracy in 1999, has not been accompanied by effective planning. To achieve inclusive development therefore, there is the need to return to development planning in order to address the destruction meted by insurgents in the North east and the lack of inclusiveness in Nigeria's growth observed in recent times.
\end{abstract}

Keywords: Output Growth, Seasonality and Stochastic Cycles, Development Planning,

\section{Introduction}

Despite several criticisms and debates calling for new measures of economic progress, gross domestic product (GDP) remains a vital statistic to assess the level of economic prosperity in developing and developed countries. The effort of several studies in the economics literature, however, have focused on examining the factors driving growth leaving fewer ones to grapple with examining seasonality's associated with growth trends. The philosophical consequence for this neglect is gross. Regression analysis which by its construction would restrict the number of variables that affect the GDP in any framework is the technique often employed in the set of studies in the first aspect of our argument, leaves out the critical side of history and the salient factors that have influenced growth over time. Analysis of growth trends, however, makes effort to explain the peaks and trough identified in growth trends within socio-economic, political and environmental context. A study by SDS (2006) noted that recurring seasonal pattern is commonly associated with economic time series. They defined seasonal adjustment as the process of estimating and removing varying seasonal effects from a time series to provide a clearer movement in the trend. Time series, they added, can be broadly decomposed into three basic components: a trend-cycle component, a seasonal component, and an irregular component (see SDS, 2006). Seasonality, which is associated with seasonal component, is the intra-year periodic variation that repeats in the period every year. Since growth rates are computed periodically, testing for seasonality would therefore be important so as to enable proper understanding of the pattern of output growth for planning purpose. Thus, this paper examines the trend of GDP (output) growth in Nigeria using data available on quarterly basis for the period 1981 to 2013. More so, it examines the seasonality in the GDP trend and also tests the smoothening power of low and high periodicity using two filters: Hodrick-Prescott and the (Christiano \& Fitzgerald, 2003). Findings from the paper would trace periods within the study period associated with high but volatile growth or low but stable growth periods in Nigeria to enable effective planning for sustainable development in Nigeria.

\section{Empirical and Theoretical Issues}

A large part of the infrastructure base available in Nigeria today was made possible by the development and rolling plans that characterized the 1980s/1990s. The absence of proper planning framework that have characterized economic management since the return to democratic governance, however, have brought 
about the use of a series of non-coherent statements (e.g. Seven Point Agenda, Transformation Agenda, etc.) as proxy for development planning. The first national development plan (1962-1968), which aimed at exploiting the abundant resources in the country to improve the living standards of the people, sought out to achieve a GDP growth target of 4\% (Federal Ministry of Economic Development, 1963). The main objective of the second national development Plan, 1970-1974, was to restore the damage caused by the civil war and to address the food shortages which resulted from the civil war and subsequently from the effect severe drought (see Anyanwu, 1997). Hence, the third national development plan (1975-1980) was essentially a continuation of the development process and policies that were initiated in the second development plan. The fourth national development plan (1981-1985) re-emphasized the need for self-reliance but, was distorted by foreign exchange shortages and scarcity of essential commodities (mostly of food items) (see Ayoola, 2001). These outcomes were contrary to the objectives of the plan which aimed at promoting social equity, price stability, economic growth and development (Anyanwu, 1997). This scenario presents a similar scenario since the fall of crude oil price in June 2014 that have decreased revenue inflow to the federal government and scarcity of foreign exchange in Nigeria.

By 1986, however, the country adopted a 15 to 20 years perspective plan, a three-year national rolling plan and one year annual budgets. National rolling plans which were implemented as follows: first national rolling plan (1990-92) with emphasis on agricultural development and provision of infrastructural facilities; second national rolling plan (1991-1993) placing priority on the completion of on-going projects in the areas of health, urban and rural water supply, education and environmental protection among others; the third national rolling plan (1993-95) set out to address the problems of depreciating value of the naira, rising inflationary trend, sluggish performance of the productive sectors and external debt; the fourth national rolling plan (1994-96) which likewise was meant to address high and unstable interest rates, unsustainable fiscal imbalances, unemployment as well as depreciating value of the naira and high rates of inflation; and the fifth national rolling plan of 1997-1999 with a major policy thrust continuing to build on the posture of the fiscal discipline and monetary restraint of the previous two years in order to sustain macroeconomic stability (see Ayoola, 2001). How the economy performed during these periods of development plans and how it differed in periods without them, would provide useful insight for development planning in Nigeria.

A study by the European Strategy and Policy Analysis System (ESPAS) identified global growth drivers to include growth in human population and human capital development. While urban growth is argued to be associated with overall income growth (see ESPAS, 2013), the World Bank (2013), however, showed that whereas empirical evidence validates this claim in Asian countries, population growth in the urban areas has not been accompanied with economic growth in most countries in Africa. Another growth driver identified in the ESPAS (2013) report is natural resources. Zuleta (2012) found that climatic factors were the main source of output fluctuations in primitive economies, and that these changes were bigger in locations farther away from the equator. Hence they deduced that there is a positive correlation between geographic location and GDP per capita. The model used in Zuleta (2012) assumed that output behaves cyclically and technology play a role in consumption smoothening. Under such conditions, they argued that savings would be bigger in places with larger changes in output. However, adopting capital intensive models of production in economies where seasonal fluctuations are stronger would help boost productive activities. The deduction from Zuleta (2012) is that wide fluctuations identified in the GDP trend of developing economies, could be linked to the lack of technology use in their primary sectors like agriculture.

There are different methods to extract seasonality in time series analysis. The regression method specifies unobserved components as deterministic functions of time. Given that economic time series are mostly characterized by moving trends and by evolving seasonal patterns, this method is criticized for being restrictive and inapplicable in many cases hence, replaced by more flexible procedures, such as moving averages methods for filtering (see Planas, 1998). Following Planas (1998), the linear time invariant filter is specified below:

$a(B)=\sum_{k=-m}^{r} a_{k} B^{k}$ 
Where ${ }^{a_{i}}$ are the weights (using real numbers), independent of time and satisfy $\sum a_{i}=1$ and ; $\sum a_{i}^{2}<\infty$; for a linear filter with distance from one observation to the other. According to Priestley (1981), such filters do not induce phase shift in the filtered series hence, if $m=r$, and $a(B)$ is a seasonal filter, the seasonal component estimator following Planas (1998), would be expressed as:

$\hat{s}_{t}=\left[a_{0}+\sum_{k=1}^{r} a_{k}\left(B^{k}+B^{-k}\right)\right] x_{t}$

Hence, $\hat{s}_{t}=a(B) x_{t}$

Another filter commonly used in macroeconomics to extract a trend component from a time series is the Hodrick-Prescott (HP) filter (see de Jong and Sakarya, 2013). It is used to separate the long run trend in a data series from short run fluctuations. While it seems intuitively clear that no smoothing technique should be equally well applicable to all types of trended macroeconomic data, the HP filter is universally used in macroeconomics.

According to de Jong and Sakarya (2013), the HP filter smoothed series $\hat{\tau}_{T}=\left(\hat{\tau}_{T 1}, \hat{\tau}_{T 2}, \ldots, \hat{\tau}_{T T}\right)^{\prime}$ as introduced into Economics in Hodrick and Prescott (1997) results from minimizing, over all

$\tau \in \square^{T}$,
$\sum_{t=1}^{T}\left(y_{t}-\tau_{t}\right)^{2}+\lambda \sum_{t=2}^{T-1}\left(\tau_{t+1}-2 \tau_{t}+\tau_{t-1}\right)^{2}$,

Where T denotes sample size, $\lambda$ is a (nonnegative) smoothing parameter, $y$ is the series to be smoothed. The

$\hat{\tau}_{T t}$ are typically referred to as the trend component, which together with the cyclical component, are weighted average of the yt. Other properties of the HP filter are:

$\hat{\tau}_{T t}\left(y_{1}+1, y_{2}+1, \ldots, y_{T}+1\right)=\hat{\tau}_{T t}\left(y_{1}, y_{2}, \ldots, y_{T}\right)+1$, and therefore $\sum_{s=1}^{T} w_{T t s}=1_{\text {for }} t \in\{1,2, \ldots, T\}$

Also, $\quad \hat{\tau}_{T t}(1,2, \ldots, T)=t$, implying that $\sum_{s=1}^{T} w_{T t s}=t$ for $t \in\{1,2, \ldots, T\}$. In this way, however, a quadratic trend cannot be absorbed into $\hat{\tau}_{T t}$.

\section{Trend Analysis and Discussion}

Using HP and C-F filter, this section examines the seasonality associated with Nigeria's GDP growth. The data used are quarterly data on gross domestic product (GDP) on Nigeria from 1981 to 2013. Quarterly data trend for GDP by agricultural sector, industry and services were also examined. Figure 1 shows that quarterly fluctuation of GDP by Agriculture, Industry, Service sector and over GDP from 1981 to 2013 in Nigeria. The trend of agriculture shows increase effect of seasonality on the performance of the agricultural sector. Its contribution to the growth of the economy that was stable in the 1980s began to witness some fluctuation that suggests seasonal behavior. The trend in the share of industry contribution to GDP also shows an increasing behavior that is also characterized with wide swings. This reflects the difficulty in getting industrial policy right and more importantly, getting industries to work in Nigeria. The services sector has also recorded increase in its share of GDP driven by revolution in the telecom, banking and entertainment industry in Nigeria. Taken together, these sectors have helped to contribute to the overall growth of the Nigerian economy. 
Fig 1(a): Agric GDP: 1981:Q1 - 2013:Q4 $\quad$ Fig 1(b): Industry GDP: 1981:Q1 - 2013:Q4
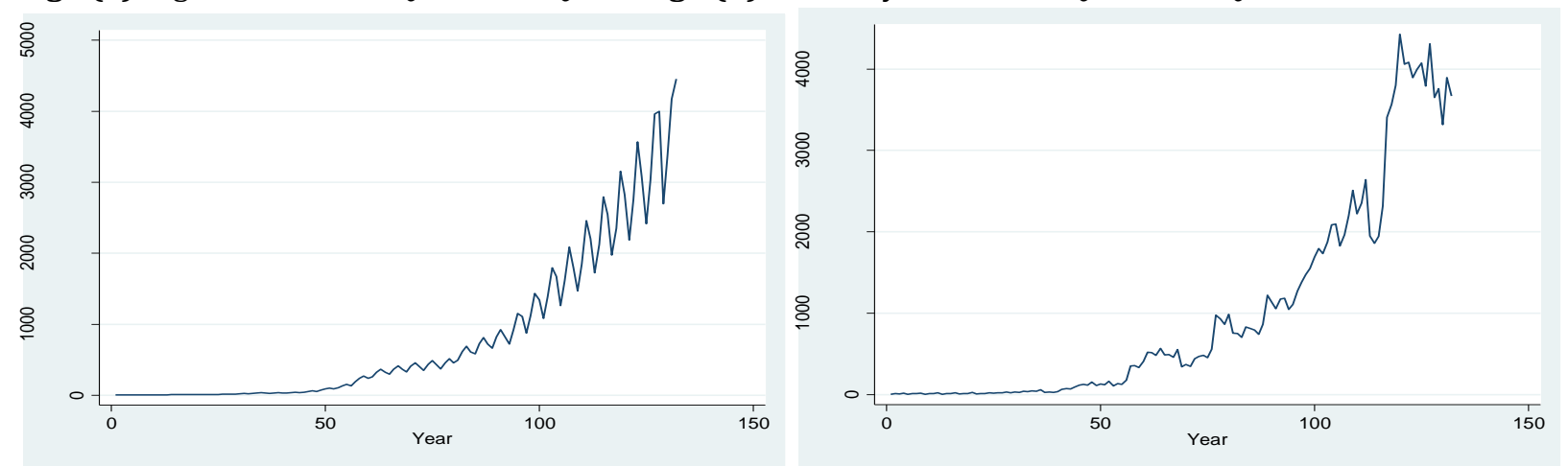

Fig 1(c): Services GDP: 1981:Q1 - 2013:Q4 Fig 1(d): GDP growth: 1981:Q1 - 2013:Q4

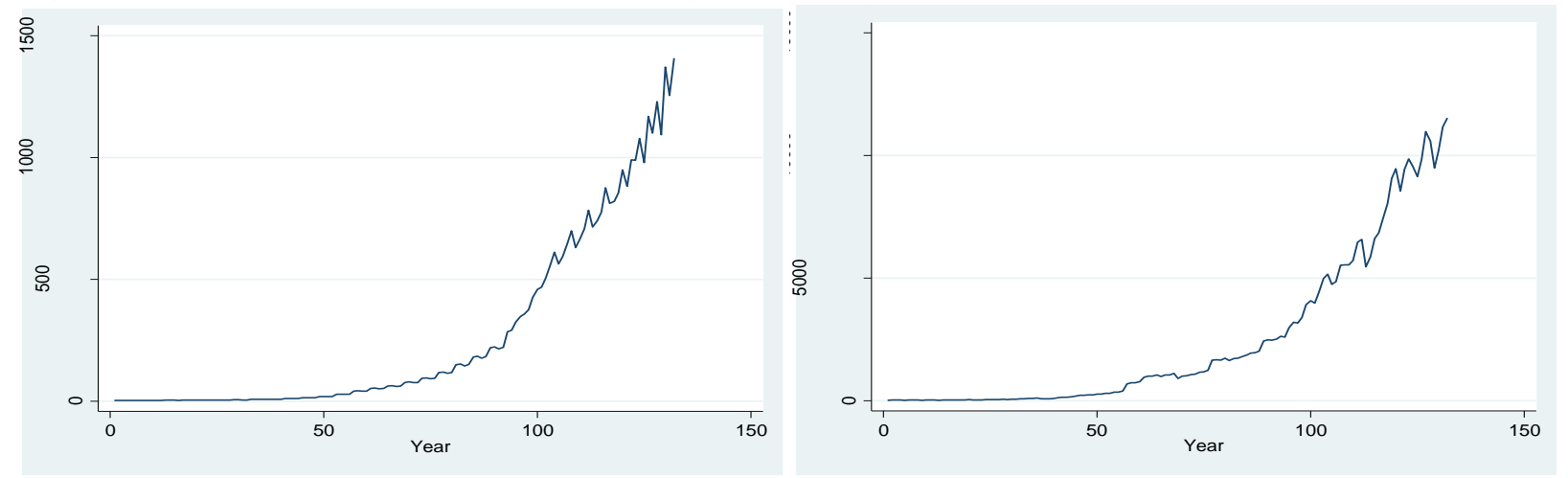

Using the HP filter, the sample spectrum density function for GDP growth was deduced. The periodogram (see Fig $2 \mathrm{a}$ and $2 \mathrm{~b}$ ) shows periods of high and periodicity in the trend of Nigeria's GDP. The line above -6 (to the left of the left-hand vertical line) in Fig 29a), however, reveals that high-periodicity stochastic cycles were not filtered with the default value smoothing parameter. That there is no tendency of the points to the right of the right-hand vertical line to be smoothed toward -6 also reveals that the HP filter did not remove any of the low-periodicity stochastic cycles. Thus using the Christiano \& Fitzgerald (2003) filter (following Hurn, 2004), we estimated the sample spectrum function. This time, the high-periodicity stochastic cycles were removed.

Fig 2(a):GDP Spectral density function (HP Filter) Fig 2(b):GDP spectral density function (CF Filter)
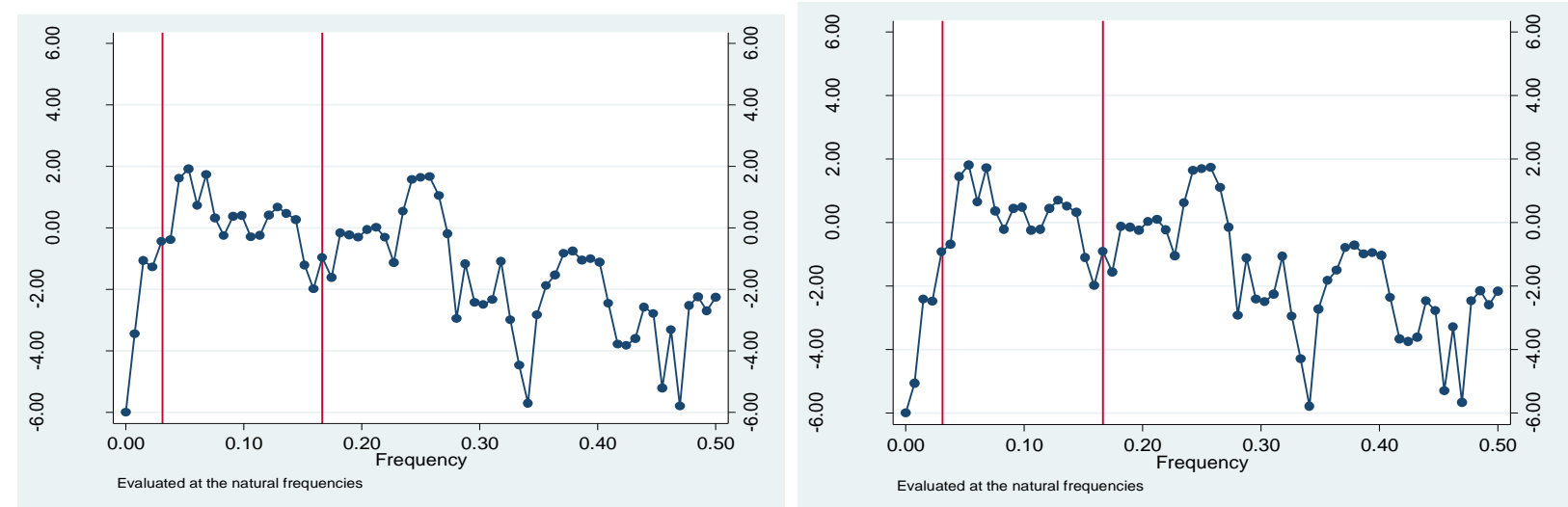

We also estimated the growth rate of quarterly GDP in Nigeria following Hurn (2004) and smoothed the GDP series as well (see Figure 3). The result shows that, growth rate was higher in the 1980s at the same time 
more volatile. This was due to the reliance on importation for all domestic needs and critical points in the history in the global crude oil market. Growth in recent times, however, has been low but stable. The instability and fluctuations in Agriculture, Industry and Services increases imports, which affects the demand for foreign exchange. This would further dampen domestic absorption and continue the fuelling of double digit inflation in the system as well as debt increase. Nonetheless, the prevailing thinking in the Nigerian economic space has not taken adequate account of how prolonged recessions or slow economic recoveries of key sectors can undermine future economic growth, jobs, and wages. This would obviously have long-term consequences of a recession for the increasing population. Part of the fluctuations in GDP contributions from agricultural in recent times may be due to lack of research focus on maintaining and improving yields and conservation of natural resources and the environment. It is likely climate change concerns also contributed to the fluctuations. Further, the linkage between the sectors is at best weak and a decline in any one sector would affect the others negatively. There is no doubt that Nigeria's position as an agricultural powerhouse has declined, and steeply. While Nigeria once provided 18 percent of the global production of cocoa, second in the world in the 1960s, that figure is now down to 8 percent. And while the country produces 65 percent of tomatoes in West Africa, it is now the largest importer of tomato paste. Nigeria's oil sector has come at the detriment of the agricultural and industrial sectors, and that is why there is a rising poverty situation. Economic theory posits that the ability of aggregate demand management to expand output is limited by the basic infrastructure in the economy and the rate of technological progress. These factors are at best very weak in the Nigerian context. Thus, restructuring the system to support high levels of aggregate demand could create conditions that could expand capacity of both the Agricultural and Industrial sectors.

Fig 3(a): Nigerian GDP Growth Rate $\quad$ Fig 3(b): Nigerian GDP Growth Rate (Smoothed)

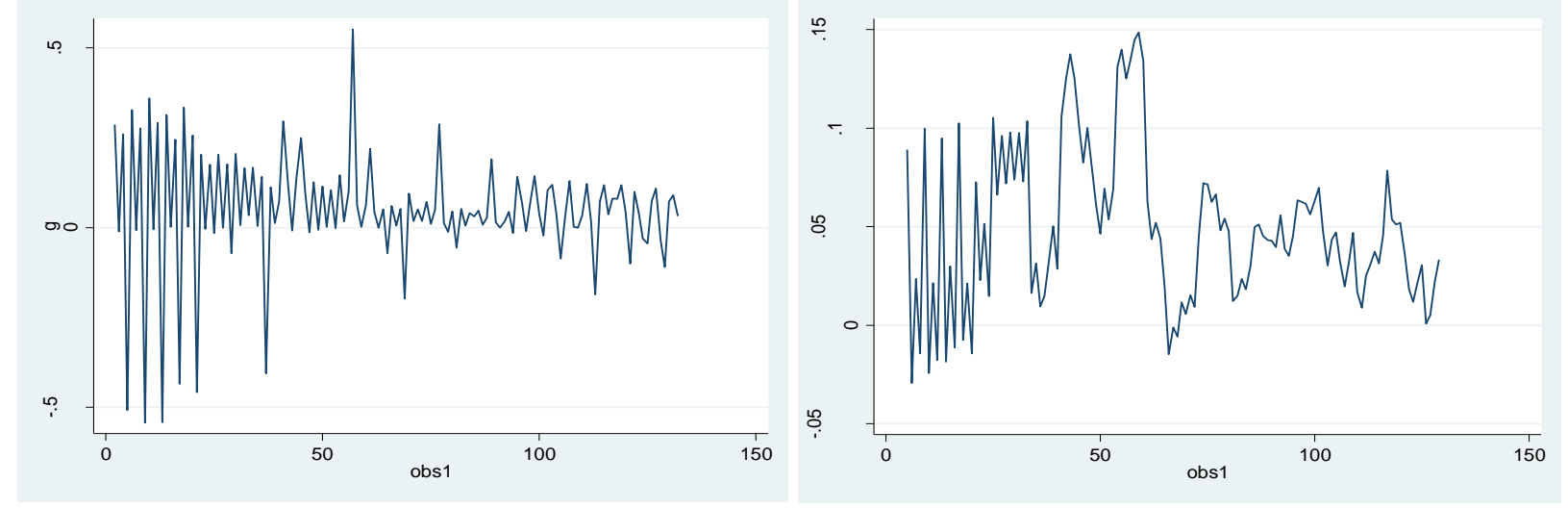

\section{Summary and Conclusion}

The seasonality associated with GDP growth in Nigeria was examined using quarterly data for the period 1981 to 2013. Empirical evidence favored the strength of the C-F filter in removing low-periodicity stochastic cycles associated with output growth in Nigeria compared to the HP filter. The smoothed GDP trend further revealed that growth rate was higher in the 1980s/1990s but volatile unlike the stable but low growth observed since 1999. However, Nigeria is not alone in the decline and fluctuations of the key growth drivers. Developing economies such as China, India and Brazil, which had boosted global recovery since 2009 - are also fluctuating. Chinese manufacturing weakened in 2012; India is experiencing the lowest growth in a decade; and the Brazilian economy has not been steady since 2012. Ironically, the current Naira's depreciation should have been a boost to support manufacturing and agricultural exports over the rest of the year, as it makes local exports more competitive and dampens demand for imports. But the economy is not productive at the moment, fuelling concerns of more fluctuations in the Agriculture, Industry and Service sectors. If current economic trends persist, economic aggregates in Nigeria will be constrained by the global effects of oil prices as well as the likelihood of further industrial action by organized labour for the perennial electricity shortages in the system.

To re-invent itself, on the path to modern development development, Nigeria should examine what factors contributed to the fluctuations in its GDP within the period. The paper concludes that, economic structures 
and frameworks that helped fueled growth in the 1980s - such as development plans and holistic agricultural planning, would be useful in achieving sustainable economic growth in Nigeria. This has become imperative, especially, as the country is planning a holistic reform to address its development challenges emanating from exclusiveness observed in its growth process in recent times and disruption in insurgency activities (Boko Haram) in the country. The following recommendations are suggested:

- The Federal Government of Nigeria should commit to a more ambitious programme of support for agricultural R\&D investment and the Industrial sector so as to slow or reverse the fluctuations observed. It is obvious that lags between R\&D investments and productivity growth are very long, but certainly results would show in subsequent periods.

- Furthermore, the Government is encouraged to embrace the relatively new agricultural biotechnologies and the benefits of countries that have adopted them. This would provide a consumption push for the Agriculture, Industry and Service sectors.

- Policy makers should also make clear what the policy responses will be on the economic framework with emphasis on Agriculture and Industry. This would generate backward linkages for the service sector.

In general, not nearly enough analysis has been undertaken on the potential of seasonal fluctuations of Agriculture, Industry and Services in the Nigerian scenario. Further research can also explore deeply, the mechanisms by which seasonal fluctuations can have long-term damaging consequences on the economy.

\section{References}

Anyanwu, J. C. (1997). Structure of the Nigerian Economy: 1960-1997. Onitsha: Joanee Publications.

Ayoola, G. B. (2001). Essays on the Agricultural Economy I: A Book of Readings on Agricultural Development Policy and Administration in Nigeria. Ibadan; T.M.A Publishers

Christiano, L. J. \& Fitzgerald, T. J. (2003). The band pass filter. International Economic Review, 44, 435-465.

ESPAS. (2013). The Global Economy in 2030: Trends and Strategies for Europe' European Strategy and Policy Analysis System (ESPAS) Publication (November) edited by D. Gros and C. Alcidi

Federal Ministry of Economic Development, Nigeria. (1963). National Development Plan 1962-68, Lagos.

De Jong, R. M. \& Sakarya, N. (2013). The Econometrics of the Hodrick-Prescott filter' Available online: http://econ.ohio-state.edu/seminar/papers/131007_Sakarya.pdf

Hodrick, R. J. \& Prescott, E. C. (1997). Postwar U.S. Business Cycles: An Empirical Investigation. Journal of Money, Credit, and Banking, 29, 1-16.

Hurn, S. (2004). A First Tutorial in STATA' Queensland University of Technology' National Centre for Econometric Research.

Planas, C. (1998). The Analysis of Seasonality in Economic Statistics: A Survey of Recent Developments. QUESTIIO, 22(1), 157-171.

Priestley, M. B. (1981). Spectral Analysis and Time Series, New York: Academic Press.

SDS. (2006). Seasonal Adjustment of Economic Time Series information paper on economic statistics Publication of the Singapore Department of Statistics (SDS).

World Bank. (2013). Turn Down the Heat, Climate Extremes, Regional Impacts, and the Case for Resilience, A Report for the World Bank by the Potsdam Institute for Climate Impact Research and Climate Analytics, June.

Zuleta, H. (2012). Seasonal Fluctuations and Economic Growth. Journal of Economic Development, 37(4), 1-27. 